\title{
Role of Pre And Postoperative Topical Cyclosporine (0.05\%) on Recurrence in Recurrent And Vascularised Pterygium
}

\author{
Sanjay Kumar Dhar ${ }^{1}$,Gaurav Kapoor ${ }^{2}$, JKS Parihar $^{3}$ \\ ${ }^{1}$ (Department Of Ophthalmology, CH (SC), Pune,India) \\ ${ }^{2}$ (Department Of Ophthalmology, ,Base Hospital ,Delhi Cant, India) \\ ${ }^{3}$ (Addl DGAFMS (MR,H\&Trg),O/O DGAFMS ,New Delhi, India)
}

\begin{abstract}
Purpose: Randomised study to evaluate the role of Cyclosporine eye drops (0.05\%) pre \& postoperatively on recurrence in cases of recurrent \& vascularized pterygium, undergoing excision and Conjunctival Limbal Autograft with Fibrin glue.

Materials and Methods: In this prospective study 100 eyes of 100 patients were taken up for study in two groups - Group A (50 eyes) and Group B (50 eyes). Only those eyes that had recurrent or vascularised pterygium were included in the study. Each case in both the groups underwent conjunctival limbal autograft with fibrin glue, after excision of pterygium. Group A received topical Cyclosporine eye drops $(0.05 \%)$ pre \& postoperatively 12 hourly for 04 weeks each, and in addition they also received topical steroids postoperatively for four weeks in tapering doses. Group B received standard of care treatment NSAIDs pre \& postoperatively for 04 weeks each and topical steroids in tapering doses for four weeks postoperatively. Any encroachment of conjunctiva more than $1 \mathrm{~mm}$ inside the limbus was considered as recurrence. Postoperatively patients were followed for recurrence, adverse effect and complications for 06 months in the two groups.

Results: Recurrence was seen in 03(6\%) of eyes in Group A and 04(8\%) of eyes in Group B.

Conclusion: Both pre \& postoperative use of topical Cyclosporine (0.05\%) can be efficacious in further reducing the chances of recurrence after pterygium surgery, although the difference observed was not statistically significant (RR-0.75, P Value-0.69).
\end{abstract}

Keywords: Pterygium-recurrent and vascularized, Limbal Stem cell Transplant, Fibrin Glue, Cyclosporine eye drops.

\section{Introduction}

Pterygium is characterized by tissue remodelling, cellular proliferation, neovascularization, and inflammation [1-2]. A stromal overgrowth of fibroblast and blood vessel is accompanied by an inflammatory cell infiltrate and abnormal extracellular matrix accumulation [3-6]. Although several hypotheses have been associated with its etiology, its pathology still remains to be explained. Secretion of pro-inflammatory cytokines such as interleukin (IL)-1, IL-6, IL-8 and tumor necrosis factor (TNF)- secondary to chronic ultraviolet (UV) radiation is a widely recognized etiological factor in pathogenesis of this lesion ${ }^{6-7}$. Among these, IL-1 plays an important role in the development process of pterygium [6-7]. The vascular endothelial growth factor (VEGF), which is known to have a role in angiogenesis, has been shown to exhibit an increase in pterygium epithelium and vascular endothelium [8-9]. VEGF is believed to be stimulated by a mediation of TNF-through UVB (ultraviolet B) induction [10]. Cyclosporine A (CsA) shows a selective effect against T-helper cells and prevents the synthesis and secretion of ILs. CsA has also been shown to block angiogenic factors induced by VEGF [1112].Based on the above evidence and due to insufficient knowledge about the role of pre \& postoperative use of topical Cyclosporine in cases of recurrent and vascularized pterygium, we studied the efficacy of topical Cyclosporine used pre \& postoperatively on the recurrence of vascularized and recurrent pterygium post surgery.

\section{Materials And Methods}

This prospective interventional study included 100 eyes of 100 patients of vascularized and recurrent pterygium, who presented in the eye OPD of a Zonal Hospital. Patients who had pseudopterygium, previous history of herpes keratitis, ocular surface disorder or pregnancy were not included in the study. Patients were divided into two groups, group A \& B, each consisting of 50 eyes of 50 patients. Both the groups underwent conjunctival limbal autograft with fibrin glue after excision of pterygium. Group A received topical Cyclosporine eye drops $(0.05 \%)$ pre \& postoperatively 12 hourly for 04 weeks each and in addition they also received topical steroids postoperatively for four weeks in tapering doses. Group B received standard of care treatment NSAIDs pre \& postoperatively for 04 weeks each and topical steroids in tapering doses for four weeks 
postoperatively. All the patients in both the groups were followed-up for recurrence (encroachment of conjunctiva ahead of limbus more than $1 \mathrm{~mm}$ ), any adverse effect and complications. The follow-up was on $1^{\text {st }}$ day, 06 weeks, 12 weeks and 06 months postoperatively. Sample size of 100 patients, 50 in each group was calculated after keeping confidence interval of $95 \%$ and was based on results of similar study [13]. The data was collected and put through statistical analysis using Chi square test.

\section{Results}

Our study included 100 eyes of 100 patients (50 eyes in each, Group A \& B). All the patients were followed-up for 06 months. The mean age in Group A was 42.1 years and in Group B was 45.0 years. The gender distribution was also seen to be statistically not significant between two groups.

Table 1- Group Characteristics

\begin{tabular}{|l|l|l|l|}
\hline Characteristics & \multicolumn{1}{|c|}{ Group A } & \multicolumn{1}{|c|}{ Group B } & Total \\
\hline Mean Age in Years & 42.1 & 45.0 & 43.55 \\
& & & \\
\hline Sex- \\
$\begin{array}{l}\text { (a) Male } \\
\text { (b) Female }\end{array}$ & 32 & 26 & 58 \\
\hline
\end{tabular}

Table 2 - Baseline Disease

\begin{tabular}{|l|l|l|l|}
\hline Disease Characteristics & \multicolumn{1}{|c|}{ Gp A } & Gp B & Total \\
\hline Vascularised pterygium & 11 & 11 & 22 \\
\hline Recurrent pterygium & 30 & 28 & 58 \\
\hline $\begin{array}{l}\text { Both (Vascularised \& Recurrent } \\
\text { pterygium) }\end{array}$ & 09 & 11 & 20 \\
\hline
\end{tabular}

The recurrence was seen in $03(06 \%)$ cases in Group A and $04(08 \%)$ cases in Group B, while recurrence did not occur in 47 (94\%) cases in Group A and 46 (92\%) cases in Group B, the relative risk being 0.75 (RR - 0.75,CI-0.18-3.1, P-Value 0.69, Chi Square test).

Table 3 - Recurrence Free Survival Rate

\begin{tabular}{|c|c|c|c|c|}
\hline Group & Recurrence (-) & $\begin{array}{l}\text { Recurrence } \\
(+)\end{array}$ & Total & $\begin{array}{l}\text { Recurrence } \\
\text { Free survival rate (\%) }\end{array}$ \\
\hline A & 47 & 3 & 50 & $94 \%$ \\
\hline B & 46 & 4 & 50 & $92 \%$ \\
\hline
\end{tabular}

No graft infection, scleral melting, epithelial defect or any other significant vision threatening complication was seen in any of the cases. Peroperatively difficulty in adherence of graft was seen in 02 eyes in Group A. Postoperatively lost graft and graft oedema was seen in 01 eye each in Group B. Retracted graft was seen in 01 eye each from Group A \& B.

\section{Discussion}

Conjunctival autograft surgery is generally regarded as the procedure of choice for the treatment of primary and recurrent pterygium, because of its efficacy and long term safety [14]. A free conjunctival graft harvested from the superior bulbar conjunctiva is sutured in place over the bare scleral defect. A combination of conjunctival autograft with low dose $(0.2 \mathrm{mg} / \mathrm{ml})$ mitomycin $\mathrm{C}$ was shown in a prospective randomized comparative study by Frucht-Pery et al. [15] to have a significantly lower recurrence rate compared with conjunctival graft alone. Conjunctival autografts are associated with recurrence rates (ranging from 2 to 39\%) that are comparable to recurrence occurring after using mitomycin $\mathrm{C}$ and beta-irradiation, without the attendant risk of sight threatening complications associated with mitomycin C [14].

Fibrin glue (or Tisseel) has been used as an alternative to sutures for securing conjunctival grafts [1617]. Fibrin glue also provides a more uniform attachment of the graft to the scleral bed. Most cases performed with fibrin adhesive healed with minimal inflammation and there are only sporadic cases of graft dislodgement or loss. In a retrospective study, Koranyi et al. [17] demonstrated a pterygium recurrence rate of $5.3 \%$ with glue versus $13.5 \%$ with sutures. They suggested that immediate adherence of the graft and the lack of postoperative inflammation may inhibit fibroblast ingrowth and reduce recurrence. Our study showed recurrence rate in group A (6\%) comparable to the above study. Bahar et al. [18] showed that the use of fibrin glue was associated with a significantly shorter operative time and greater patient acceptance compared with using sutures. We observed 
loss of graft tissue in $01(1 \%)$ patient, difficulty in adherence of graft during surgery in $02(4 \%)$ patients, one in each group and graft retraction in $02(4 \%)$ patients one in each group.

There are various studies in which topical cyclosporine was used although with different surgical techniques and mostly in primary pterygium. Turan Vural et al who compared bare sclera versus bare sclera and topical cyclosporine showed the recurrence of $44.4 \%$ \& $22.2 \%$ respectively [19]. Tok et al. used cyclosporine following primary excision in primary pterygium cases, and observed the recurrence of $12.9 \%$ [13], Aydin et al who used topical cyclosporine with conjunctival limbal autograft observed a recurrence of $3.4 \%$ [20] and Ozulken K et al observed a recurrence of $7.7 \%$ with cyclosporine [21].

Our recurrence rate was 06\% in the Cyclosporine group (Group A), which was more than the recurrence observed by Aydin et al. [20] (3.4\%) but lower than that observed by Tok et al. [13](12.9\%). It may be higher than observed by Aydin et al because of the study population of only vascularized and recurrent pterygium, which is more prone for higher recurrence compared to primary pterygium.

Although the recurrence rate between the two groups was not statistically significant, we believe that topical Cyclosporine is safe and effective in reducing recurrence rates, however, there is a need for increasing the size of study population, which should also include cases of primary pterygium, and the follow-up time should also be atleast one year.

\section{References}

[1]. M.T. Coroneo, N. Girolamo, D. Wakefield, The pathogenesis of pterygia, Curr Opin Ophthalmol, 10, 1999, 282-288.

[2]. J.C. Hill, R. Maske, Pathogenesis of pterygium, Eye, 3, 1989, 218-226.

[3]. M.E. Cameron, Histology of pterygium: an electron microscopic study, Br J Ophtalmol, 67, 1983, $604-608$.

[4]. C.M. Chan, Y.P. Liu, D.T. Tan, Ocular surface changes in pterygium, Cornea, 21, 2002, 38-42.

[5]. I.J.Wang, W.T. Lai, S.W. Liou, Impression cytology of pterygium, J Ocular Pharmacol Therap, 16, 2000, 519-528.

[6]. N. Di Giriloma, J. Chui, M.T. Coreneo, D. Wakefield, Pathogenesis of pterygia : role of cytokines, growth factors, and matrix metalloproteinases, Prog Retin Eye Res, 23(2), 2004, 195-289.

[7]. N.D. Girolama, R.K. Kumar, M.T. Cornea, D. Wakefield, UVB Mediated indication of interleukin-6 and 8 in pterigia and cultured human pterygium epithelial cells, Inves Opthalmol Vis Sci, 143(119), 2002, 3430-3437.

[8]. N. Dushku, T.W. Reid, P53 expression in altered limbal basal cells of pingueculae, pterygia, and limbal tumors, Curr Eye Res, 16(12), 1997, 1179-1192.

[9]. D.T. Tan, W.Y. Tang, Y.P. Liu, H.S. Goh, D.R. Smith, Apoptosis and apoptosis related gene expression in normal conjunctiva and pterygium, Br J Ophthalmol, 84(2), 2000, 212-216.

[10]. S. Yosihada, M. Ono, T. Shono, et al. Involvement of interleukin-8, vascular endothelial growth factor, and basic fibroblast growth factor in tumor necrosis factor alpha-dependent angiogenesis, Mol Cell Biol , 17(7), 1997, 4015-4023.

[11]. N. Pucci, E. Novembre, A. Ciaferoni, et al. Efficacy and safety of cyclosporine eyedrops in vernal keratoconjunctivitis, Ann Allergy Asthma Immunol 89(3), 2002, 298-303.

[12]. B. Strong, W. Farley, M.E. Stern, S.C. Pflugfelder, Topical cyclosporineinhibits conjunctival epithelial apoptosis in experimental murine keratoconjunctivitis sicca, Cornea, 24(1), 2005, 80-85.

[13]. O. Yalcin Tok, A. Burcu Nurozler, G. Ergun, F. Akbas Kocaoglu, S. Duman, Topical cyclosporine A in the prevention of pterygium recurrence, Ophthalmologica, 222(6), 2008, 391-396.

[14]. A. Sharma, A. Gupta, J. Ram, A. Gupta, Low-dose intraoperative mitomycin-C versus conjunctival autograft in primary pterygium surgery: long-term follow-up, Ophthalmic Surg Lasers, 31, 2000, 301-307.

[15]. J. Frucht-Pery, F. Raiskup, M. Ilsar, et al. Conjunctival autografting combined with low-dose mitomycin C for prevention of primary pterygium recurrence, Am J Ophthalmol, 141, 2006, 1044-1050.

[16]. H.S. Uy, J.M. Reyes, J.D. Flores, R. Lim-Bon-Siong, Comparison of fibrin glue and sutures for attaching conjunctival autografts after pterygium excision, Ophthalmology, 112, 2005, 667-671.

[17]. G. Koranyi, S. Seregard, E.D. Kopp, The cut-and-paste method for primary pterygium surgery:long-term follow-up, Acta Ophthalmol Scand, 83, 2005, 298-301.

[18]. I. Bahar, D. Weinberger, G. Dan, R. Avisar, Pterygium surgery: fibrin glue versus Vicryl sutures for conjunctival closure, Cornea, $25,2006,1168-1172$.

[19]. Turan-Vural et al. The effect of topical $0.05 \%$ cyclosporine on recurrence following pterygium surgery, Clinical Ophthalmology, 5 , 2011, 881-885

[20]. A. Aydin, K. Karadayi, U. Aykan, G. Can, K. Colakoglu, A.H. Bilge, Effectiveness of topical cyclosporin A treatment after excision of primary pterygium and limbal conjunctival autograft, J Fr Ophtalmol, 31(7), 2008, 699-704.

[21]. K. Ozulken, M. Koc, O. Ayar, H. Hasiripi, Topical cyclosporine A administration after pterygium surgery, Eur J Ophthalmol. 22, 2012, Suppl 7:S5-10. 